\title{
FALL IN SKIN TEMPERATURE DURING EXERCISE
}

\author{
Teruo NaKaYama, Yoshito Ohnuki, and Ken-ichi Niwa \\ Department of Physiology, Osaka University School of Medicine, \\ Kita-ku, Osaka, 530 Japan
}

\begin{abstract}
During light work using the arm in a warm environment, skin temperatures of the arms and chest fell and remained at lower levels during work. The fall in skin temperature during work was not observed in a cool environment. The fall in skin temperature was nearly proportional to work intensity and was observed in both static and dynamic work. Leg work of moderate intensity produced an initial decline and a subsequent rise in skin temperatures of the hands, thighs and legs. A significant fall in skin temperature was observed not only in the foot but also in inactive regions such as the epigastrium. The mean skin temperature remained practically unchanged during work. The fall in skin temperature during work was not due to increased evaporative cooling, but was the result of segmental vasoconstriction probably caused as a reflex in the spinal cord by non-thermal afferents from exercising muscles or moving tissues. The effect of thermoregulatory vasodilation was reduced by the reflex vasoconstriction caused by non-thermal factors. The rise in internal temperature during work could be explained by decreased heat loss due to persistently lower skin temperature.
\end{abstract}

During exercise, rectal temperature rises above the resting level almost linearly with increase in oxygen consumption. At each level of work intensity, the rectal temperature rises to the same level throughout a wide range of ambient temperatures between 5 and $30^{\circ} \mathrm{C}$ (NIELSEN, M., 1938). This observation has been repeatedly confirmed (BERGGREN and Christensen, 1950; EichNA et al., 1950; WYNDHAM et al., 1952-3; LIND, 1963). The rise in rectal temperature is not due to failure of body temperature regulation, but has been attributed to a setting of the body thermostat at a higher level. Since then, the cause of this regulated rise, often called the exercise or work factor, has been the subject of intense study and a matter of controversy.

The increase in esophageal temperature was found to be the same regardless of the kind of work performed, i.e., arm work, leg work, continuous work or inter-

Received for publication April 25, 1977

中山昭雄, 大貫義人, 丹羽健市 
mittent work, if the rate of metabolic energy production was the same (NIELSEN, B., 1968). In treadmill experiments, total heat production is much higher during downhill work than during uphill work when compared using the same work load. The rise in deep body temperature, esophageal or rectal, however, has been found to be linearly correlated with work intensity or with metabolic energy liberation, but not with total heat production. On the other hand, sweat rate increased in proportion to total heat production in both uphill and downhill running (NIELSEN, B., 1966). Her results seem to indicate that the rate of sweating, as a means of heat loss response, is fully responsive to increased heat load and is not responsible for a rise in internal temperature.

For a given climate, NIELSEN, M. (1938) observed little or no change in skin temperature during exercise. The sweat rate increased three- to five-fold when metabolism increased two $\cdot$ to three-fold by pedalling a bicycle ergometer. Due to increased evaporative cooling, the skin temperature during exercise was held remarkably constant. It was concluded that internal temperature must control the sweat-secreting mechanism (WInsLow and GAGGE, 1941). Although RoBINSON (1949) postulated that both skin and internal temperature participate in the control of sweating rate in a working man, he observed no increase in skin temperature during walking on the treadmill. With constant work rate at various environmental temperatures between 5 to $30^{\circ} \mathrm{C}$, the sweat rate increased nearly proportional to the increase in mean skin temperature while elevation of internal temperature remained constant (NIELSEN, B. and NIELSEN, M., 1965). Skin temperature during work thus depends mainly on the environmental temperature and seems to be independent of both internal temperature and metabolic rate (SNELLEN, 1966; SAltin et al., 1968; NiELSEN, B., 1969). The constant skin temperature during work has been regarded simply as the result of two opposing responses: thermoregulatory vasodilation causing a rise, and evaporative cooling causing a fall in skin temperature. Skin temperatures, however, remain constant even in a cool environment in which moderate exercise does not produce sweating.

In the studies mentioned above, skin temperature during exercise was discussed from the standpoint of its participation in the control of sweating. Little attention has been paid to skin temperature as an independent parameter in control of convection and radiation heat transfer from the body surface. In the present study, we observed skin temperatures of various parts of the body surface during different kinds of exercise at different ambient temperatures.

\section{METHODS}

The subjects were three male students of physical fitness and two of the authors. Their physical characteristics are as follows. K.F. (Age $21 \mathrm{yr}$, Height $1.76 \mathrm{~m}$, Body weight $74 \mathrm{~kg}$, Body surface $\left.1.85 \mathrm{~m}^{2}\right)$, H. S. $(21 \mathrm{yr}, 1.68 \mathrm{~m}, 63 \mathrm{~kg}$, $\left.1.67 \mathrm{~m}^{2}\right)$, H. I. (20 yr, $\left.1.63 \mathrm{~m}, 59 \mathrm{~kg}, 1.59 \mathrm{~m}^{2}\right)$, Y. O. (27 yr, $\left.1.75 \mathrm{~m}, 74 \mathrm{~kg}, 1.84 \mathrm{~m}^{2}\right)$, T. N. $\left(49 \mathrm{yr}, 1.66 \mathrm{~m}, 70 \mathrm{~kg}, 1.73 \mathrm{~m}^{2}\right)$. Experiments shown in Figs. 1 to 5 were 
carried out in August and September and those in Figs. 6 to 8 in October to December in a climatic chamber at ambient temperatures of 12 to $30^{\circ} \mathrm{C}$. Rectal and skin temperatures were measured with copper-constantan thermocouples once every min on a recording potentiometer with an accuracy of $0.1^{\circ} \mathrm{C}$. During arm ergometer experiments, forearm skin temperature was continuously recorded. Light exercise was used in order to minimize the effects of sweating, thermoregulatory vasodilation, and increased conductive heat flow from the exercising muscles. For arm exercise, a subject clad in shorts only sat on a chair with his elbow placed on a table. He grasped a handhold and pulled a weight of 1 to $5 \mathrm{~kg}$ using a pulley by forearm flexion for a vertical distance of $0.25 \mathrm{~m}, 25$ times per min paced by a metronome for a period of 4 or $30 \mathrm{~min}$. For leg exercise, a Monark bicycle ergometer was pedalled for 50 revolutions per min for 10,50 or $60 \mathrm{~min}$ at intensities of $0,0.5,1.0,1.5$ or $2.0 \mathrm{kp}$. In one experiment, the bicycle ergometer was operated by both arms at $50 \mathrm{rpm}$ for $60 \mathrm{~min}$ at $0.5 \mathrm{kp}$. Thermocouples and a gas mask for collection of expired gas were used while the subjects were sitting on the chair or on the bicycle ergometer in the climatic chamber.

The bicycle ergometer was mounted on a Potter bed balance with a sensitivity of $1 \mathrm{~g}$ in order to continuously record decrease in body weight throughout the experimental period. Local sweating was checked by the iodine-starch method. Expired gas was collected every $5 \mathrm{~min}$ successively in Douglas bags, and was analyzed in duplicate by a Haldane apparatus. The mean skin temperature was calculated by averaging regional temperatures weighed according to the 8-point system (HARDY and DuBors, 1938). Stability of the skin temperatures was confirmed prior to the start of exercise, usually more than half an hour after a subject entered the climatic chamber, but slight fluctuations of skin temperature were inevitable.

\section{RESULTS}

\section{Experiments using an arm ergometer}

Changes in skin temperature were recorded continuously on the exercising forearm. With the onset of dynamic arm exercise, forearm skin temperature began to fall and decreased $0.9^{\circ} \mathrm{C}$ by the end of a 4 min work period (Fig. 1). In this and all other experiments, the start of exercise was indicated to the subject by a countdown for $10 \mathrm{sec}$. Fall in skin temperature was never caused by expectation of exercise. The decrease in skin temperature was not restricted to the exercising arm; the skin temperature of the right forearm fell in a similar fashion by exercise of either the right arm or the left arm at the same level of work intensity. Fall in forearm skin temperature was also caused by sustained arm flexion. These results indicate that the decrease in skin temperature is not exercise specific and refute the possibility that increased convective heat loss due to arm movement causes a decline in skin temperature. The results of Fig. 1 were confirmed repeatedly in other subjects. The tendency noted was that, at the 


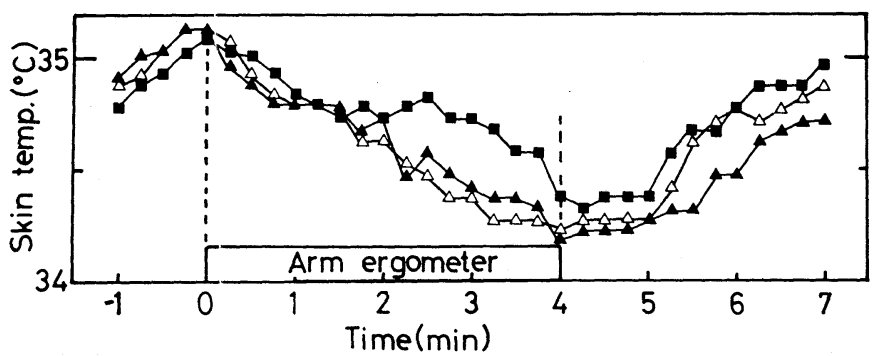

Fig. 1. Changes in skin temperature of the right forearm during periodic flexion of right $\operatorname{arm}(-\triangle-)$, left arm (- -$)$ at $4 \mathrm{~W}$ rate and during sustained flexion of right arm with a $5 \mathrm{~kg} \mathrm{(--)} \mathrm{load.} \mathrm{Forearm} \mathrm{skin} \mathrm{temperatures} \mathrm{were} \mathrm{redrawn} \mathrm{from} \mathrm{continuous} \mathrm{record-}$ ing curves. A slight rise in the skin temperature before the exercise is a part of small spontaneous fluctuations. Subj. T.N., Ambient temperature $\left(T_{\mathrm{a}}\right) 26.6^{\circ} \mathrm{C}$, r.h. $40 \%$.

same work rate, the fall in forearm skin temperature was significant when the initial skin temperature was high. Shown in Fig. 2 are the effects of ambient temperature on skin temperature change during exercise. At an ambient temperature of $26.6^{\circ} \mathrm{C}$, the forearm skin temperature fell $0.7^{\circ} \mathrm{C}$ and $0.9^{\circ} \mathrm{C}$ at the end of $4 \mathrm{~min}$ work for work intensities of $2 \mathrm{~W}$ and $4 \mathrm{~W}$, respectively. At an ambient temperature of $20.0^{\circ} \mathrm{C}$, zero load work produced a response similar to that which occurred at $26.6^{\circ} \mathrm{C}$. With an intensity of $2 \mathrm{~W}$, the initial fall was not significant and the skin temperature started to rise 1 to 2 min after the onset of work. In a cool environment of $12.8^{\circ} \mathrm{C}$, the skin temperature of the forearm fell for about $40 \mathrm{~min}$ after the subject entered the room, and then levelled off. In this state, the subject shivered occasionally and no change in skin temperature was observed with $0 \mathrm{~W}$ or $2 \mathrm{~W}$ work rate. Arm exercise at work intensity of $4 \mathrm{~W}$ caused a rise in skin temperature about $2 \mathrm{~min}$ after the onset of work without a preceding decline.

In Fig. 3, exercise of the right arm produced a temperature rise in that arm and a fall in skin temperature of the left forearm. Initial fall in skin temperature of the forearm was not significant in this figure, probably due to lower skin temperature at the beginning of exercise and lower work rate than those in Figs. 1 and 2. From the results of Fig. 1, it can be assumed that vasoconstriction of the right and left forearms took place to the same extent. If there were no vasoconstriction, the skin temperature of the right forearm during exercise would be higher. Observations, as shown in Fig. 3, were also made to localize areas which show a decrease in skin ternperature in response to right arm exercise and to see if the fall in skin temperature lasts during long-term exercise. A fall of $0.7^{\circ} \mathrm{C}$ in skin temperature on the left forearm, and a fall of $1.4^{\circ} \mathrm{C}$ on the right chest was observed during $30 \mathrm{~min}$ of exercise. The skin temperature of the thigh was not apparently affected by arm exercise. 


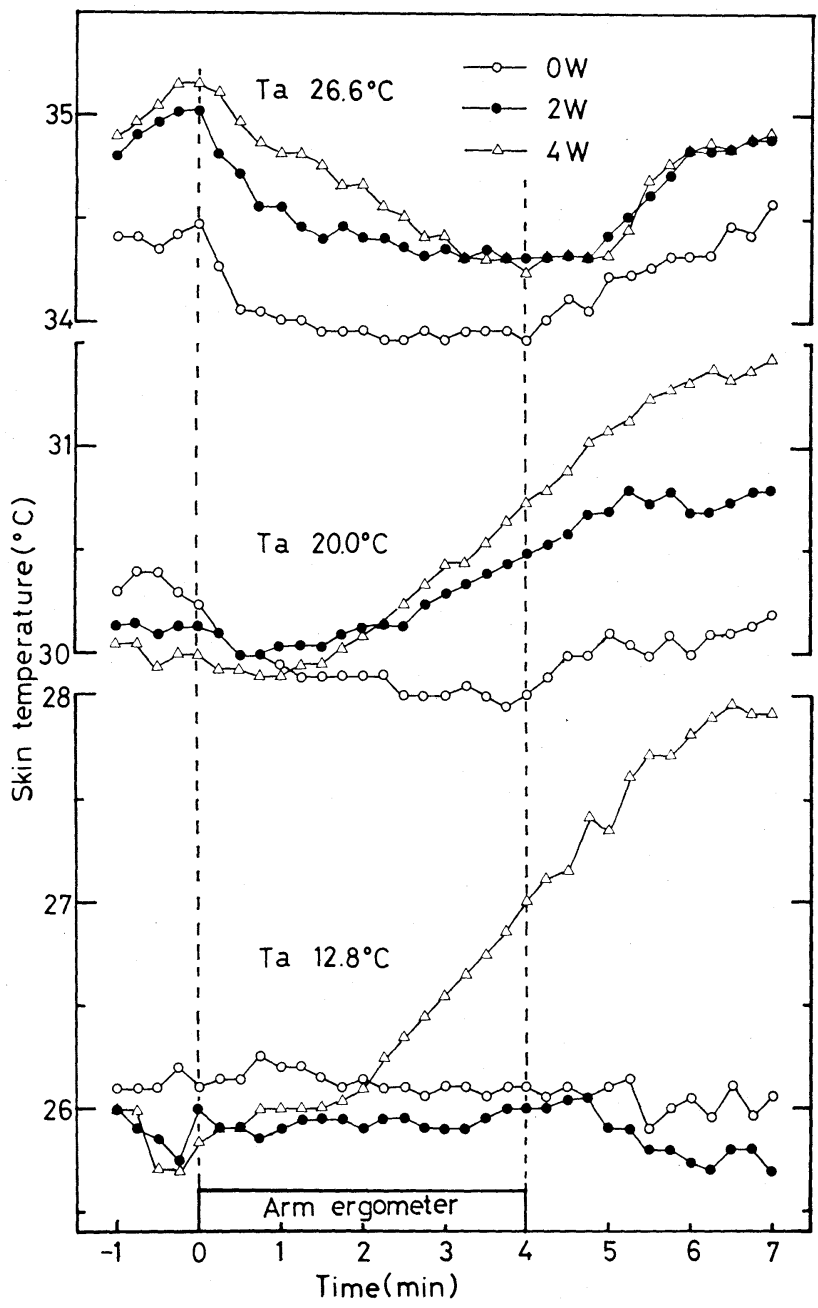

Fig. 2. Skin temperature of the right forearm during right arm exercise at different intensities and in different ambient temperatures. Subj. T.N.

\section{Experiments using a bicycle ergometer}

In an untrained subject, pedalling on the bicycle ergometer usually involves not only leg exercise, but also arm work while holding the handles. Figure 4 shows changes in skin temperature of the forearm and thigh during pedalling at various work intensities at $29^{\circ} \mathrm{C}$. In this case, a rapid drop in thigh skin temperature of about $0.5^{\circ} \mathrm{C}$ at the very beginning of pedalling was apparently caused by increased convective heat loss, because the skin temperature fell the same amount in a wind with a velocity of $0.36 \mathrm{~m} / \mathrm{sec}$, which represents the air movement at the surface of the thigh during pedalling. With increased work rate, the skin tem- 


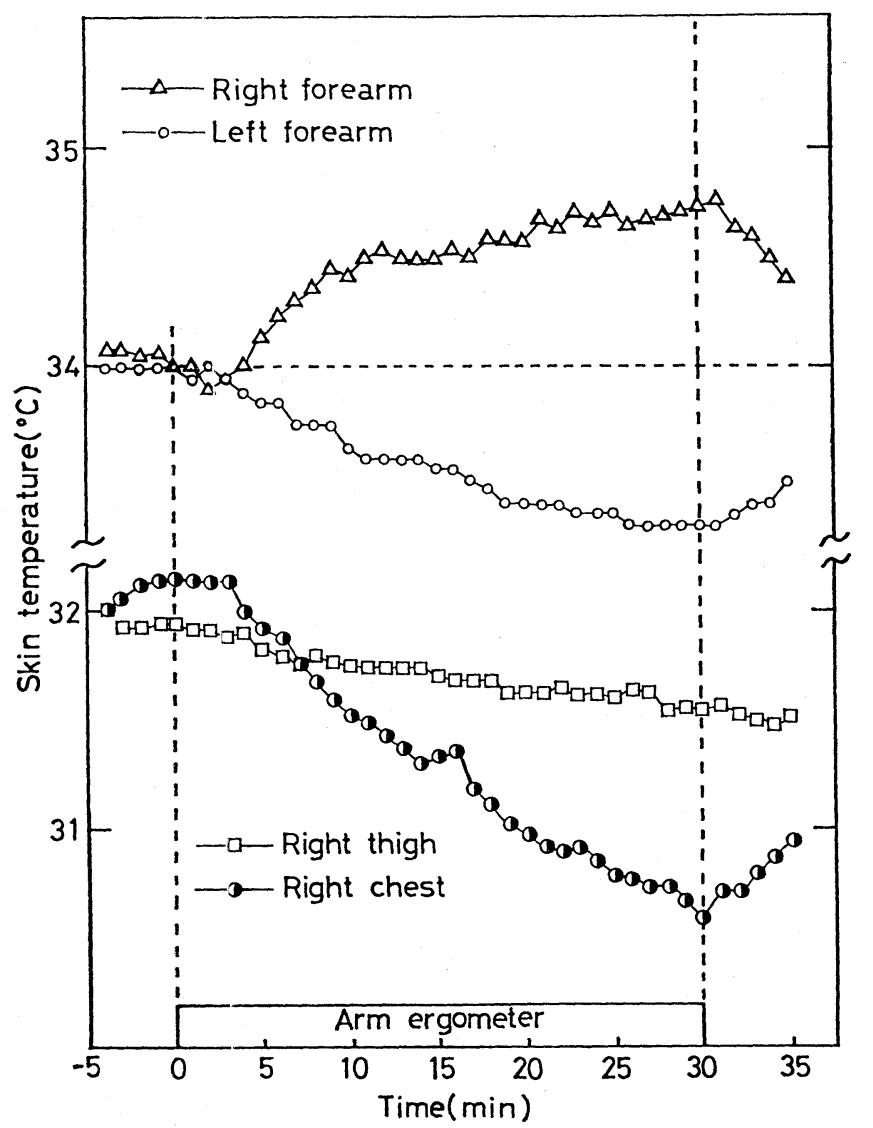

Fig. 3. Skin temperature during exercise of the right arm at $2 \mathrm{~W}$ rate. Subj. T.N., $T_{\mathrm{a}} 29^{\circ} \mathrm{C}$, r.h. $50 \%$.

perature of the thigh fell faster, turned up earlier and rose to a higher level. At the end of $10 \mathrm{~min}$ exercise, the forearm skin temperature fell $0.4^{\circ} \mathrm{C}$ and $1.1^{\circ} \mathrm{C}$ for work intensities of $50 \mathrm{~W}$ and $100 \mathrm{~W}$, respectively. No change was observed with a zero work load. Fall in skin temperature is thus proportional to work intensity. Skin temperatures on the forearm kept falling for 2 to 4 min after the end of $10 \mathrm{~min}$ leg exercise at work intensities of $75 \mathrm{~W}$ and $100 \mathrm{~W}$. On the other hand, skin temperatures on the thigh rose quickly immediately after the end of work. This is probably due to the decrease of convective heat loss and to some extent, as will be discussed, due to the fact that vasoconstrictor tone induced by exercise diminished, resulting in an increased cutaneous heat flow.

Changes in skin and rectal temperature were observed in the untrained subject T. N. during 50 min pedalling on a bicycle ergometer at a rate of $50 \mathrm{~W}$ (Fig. 5). Initial fall in skin temperature was significant in the hand, forearm, thigh and leg, 


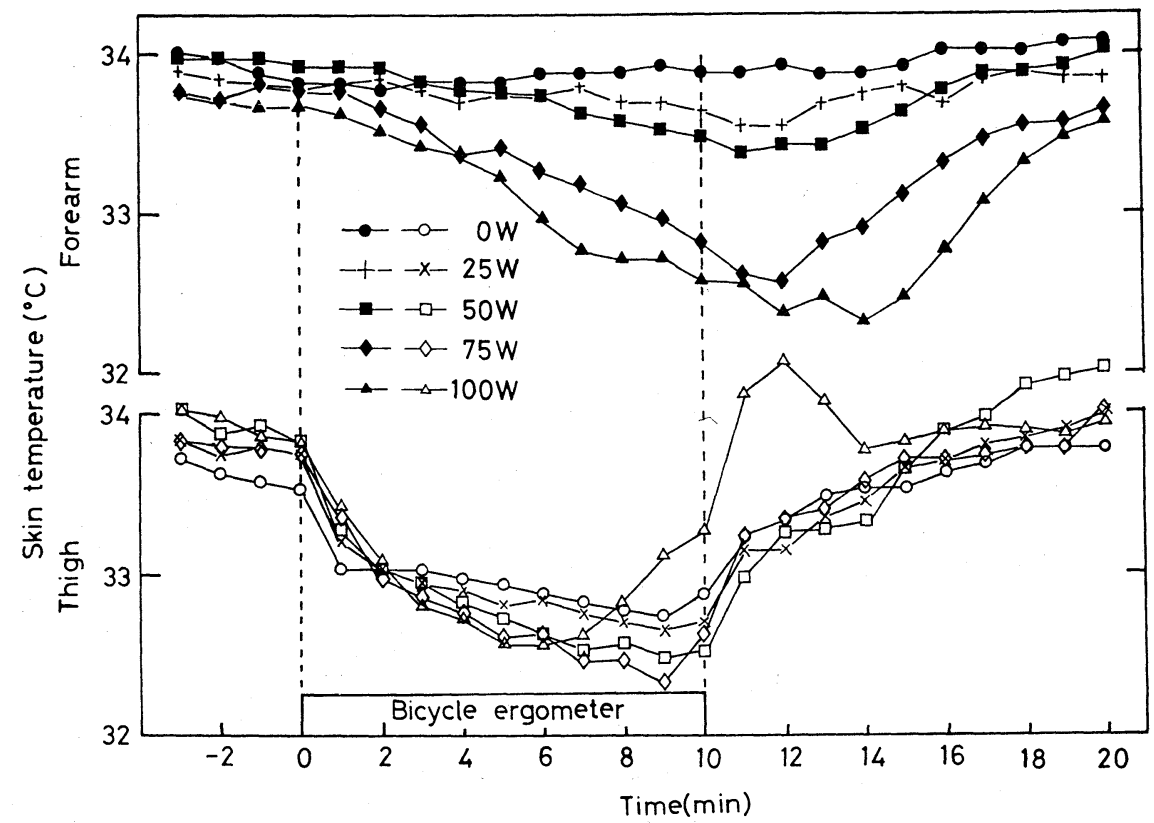

Fig. 4. Skin temperature of forearm and thigh during pedalling at different intensities. Subj. Y.O., $T_{\mathrm{a}} 29^{\circ} \mathrm{C}$, r.h. $40 \%$.

and was followed by a rise, particularly on the thigh. Skin temperature of the chest fell gradually and then rose sharply at about $20 \mathrm{~min}$ after the beginning of exercise to about $1.5^{\circ} \mathrm{C}$ above the resting level. At this stage, slight sweating was noticed on the chest causing a slight decrease in skin temperature. Immediately after the exercise, the skin temperature of the chest fell by about $3^{\circ} \mathrm{C}$ due to evaporative cooling. On the back and in the epigastrium, the skin temperature fell throughout the $50 \mathrm{~min}$ period of exercise. In spite of no sweating on the epigastrium, the skin temperature fell by $3^{\circ} \mathrm{C}$.

Heat balance measurements were made on three subjects during arm and leg pedalling. Data for Figs. 6, 7 and 8 were obtained from the subject K. F., who was accustomed to the bicycle ergometer, and are shown as representative of the experiments performed. During leg pedalling at the rate of $25 \mathrm{~W}$, neither rectal nor mean skin temperature changed, but skin temperatures changed in the characteristic ways (Fig. 6). Skin temperature rose in the thigh and fell in the foot, throughout the one hour period of exercise. On the back, the skin temperature began to fall $30 \mathrm{~min}$ after the onset of work, most likely due to increased evaporation. The leg skin temperature rose by $1.5^{\circ} \mathrm{C}$ above the pre-trial level after the initial drop and showed a sharp rise immediately after the end of exercise. A similar quick post-exercise rise in skin temperature was observed on the foot. The skin temperature of the hand fell by $1.5^{\circ} \mathrm{C}$ in the first $8 \mathrm{~min}$ and then gradually 


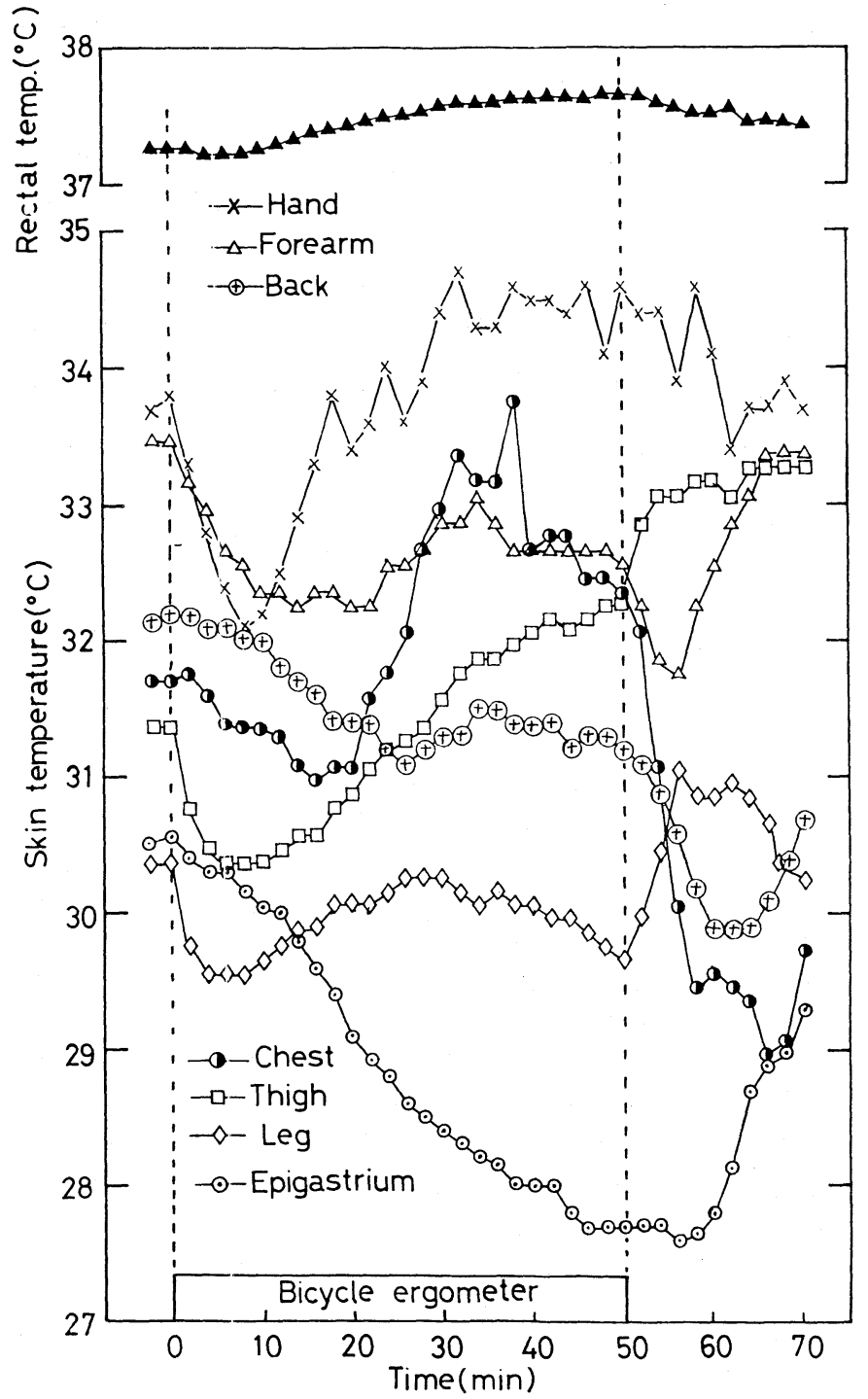

Fig. 5. Body temperature during pedalling at $50 \mathrm{~W}$ rate. Subj. T.N., $T_{\mathrm{a}} 24^{\circ} \mathrm{C}$, r.h. $50 \%$.

returned to the resting level. Skin temperatures of the head, arm, and chest did not change significantly. The metabolic rate increased from the resting level of $51 \mathrm{~W} / \mathrm{m}^{2}$ to $120 \mathrm{~W} / \mathrm{m}^{2}$ in the initial $5 \mathrm{~min}$ of work, then increased gradually to $160 \mathrm{~W} / \mathrm{m}^{2}$ in the last 5 min period. Similar results were obtained in two other subjects H. S. and H. I. Skin temperature of the foot, leg and thigh did not change when the bicycle ergometer was operated by arms, even though the work intensity 


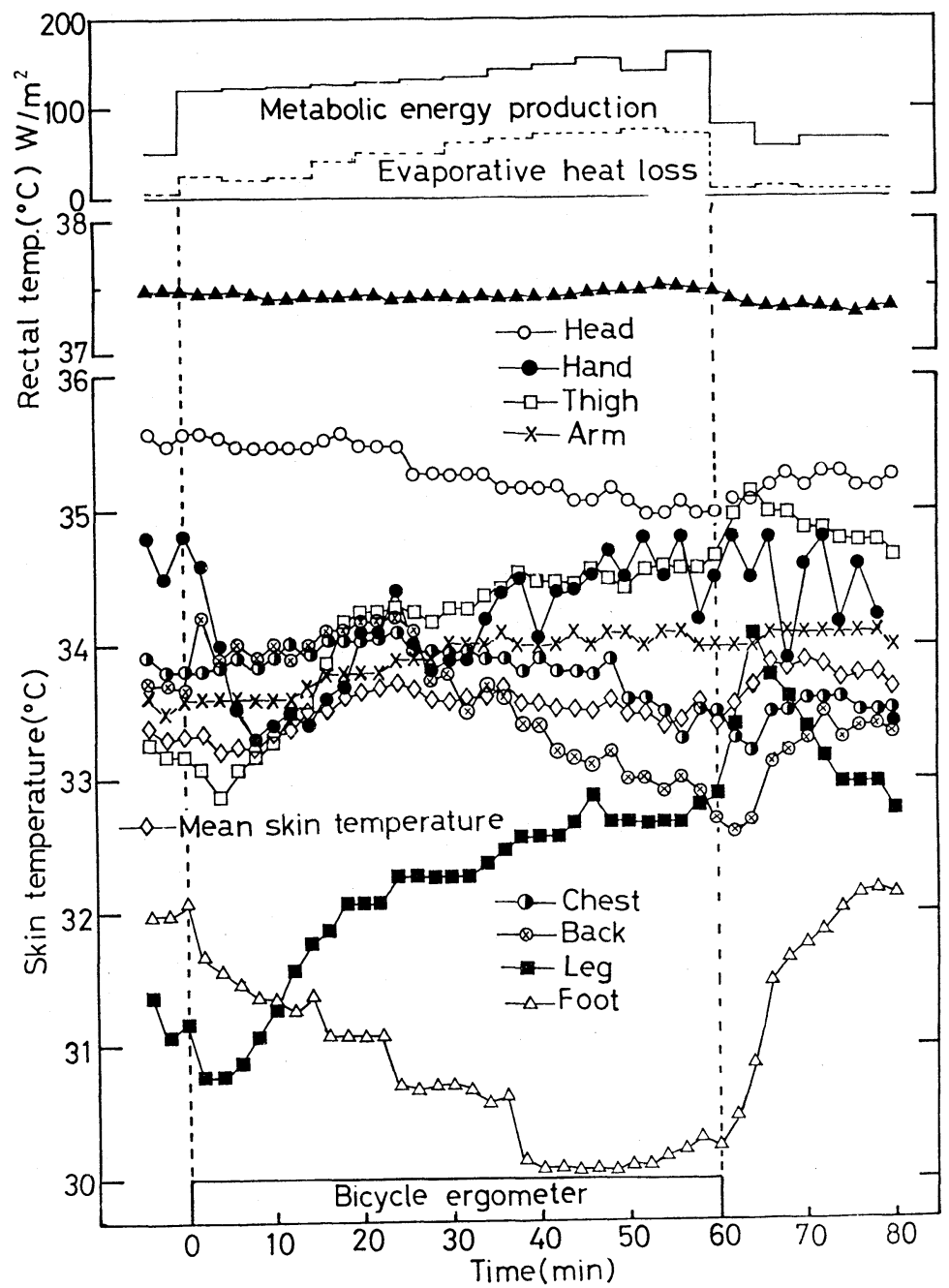

Fig. 6. Metabolism, evaporative heat loss and body temperature during leg pedalling at $25 \mathrm{~W}$ rate. Subj. K.F., $T_{\mathrm{a}} 25^{\circ} \mathrm{C}$, r.h. $50 \%$.

was the same as that of the leg exercise (Fig. 7). Both metabolic rate and evaporative heat loss increased about two-fold during the exercise. At present, the reason is not clear why there was a difference in mode of increase in metabolic rate and evaporative heat loss between the arm and the leg exercise. The chest and back skin temperatures each rose by about $1.0^{\circ} \mathrm{C}$ with no initial fall. On the other hand, skin temperature of the hand and forearm showed a significant fall at the beginning and rise at the end of the work. Post-exercise rise in skin temperature was also observed on the foot. Again the mean skin temperature did not change significantly. These findings were repeated in the other two subjects. 


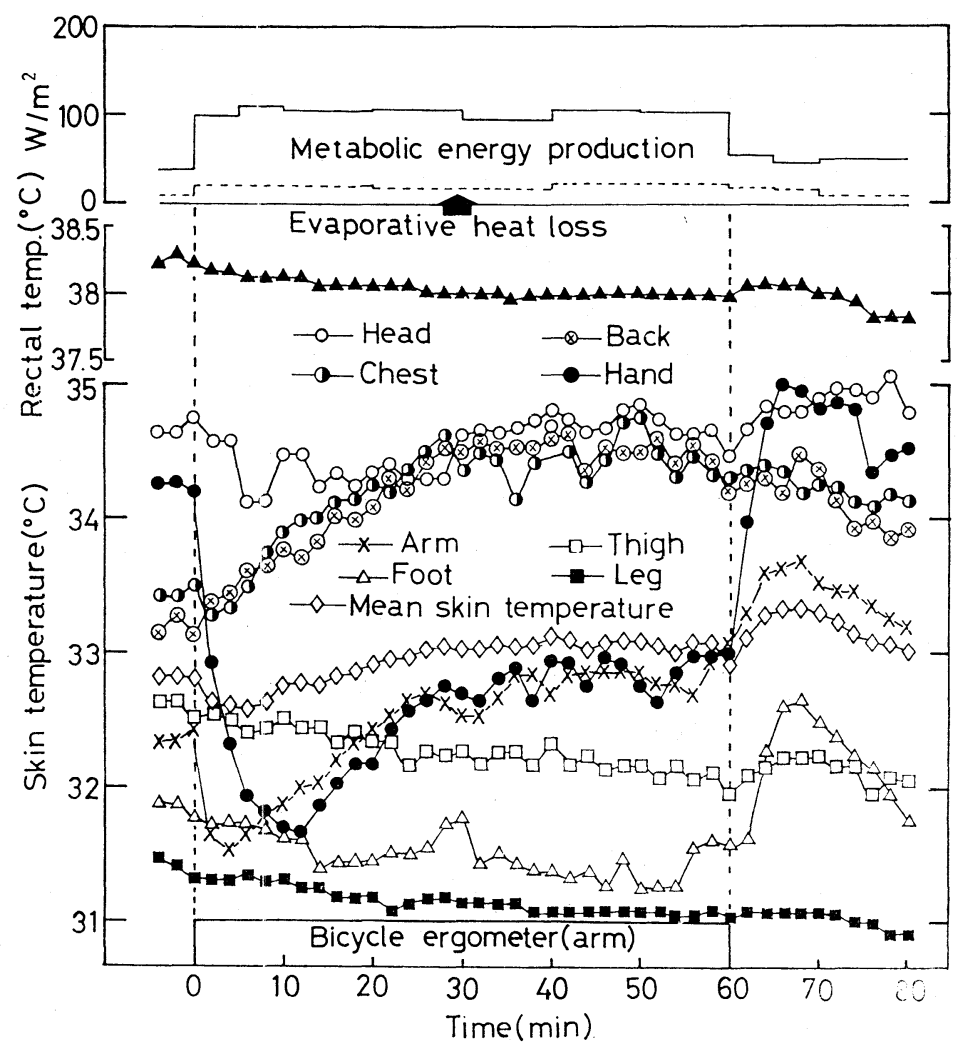

Fig. 7. Metabolism, evaporative heat loss and body temperature during arm pedalling at $25 \mathrm{~W}$ rate. Subj. K.F., $T_{\mathrm{a}} 25^{\circ} \mathrm{C}$, r.h. $50 \%$.

With leg pedalling at the rate of $100 \mathrm{~W}$, the initial fall in skin temperature of more than $1.0^{\circ} \mathrm{C}$ was observed on the hand and foot (Fig. 8). Skin temperature of the thigh rose $2.4^{\circ} \mathrm{C}$ in the first $11 \mathrm{~min}$ and then began to fall, probably due to increased sweating. The mean skin temperature did not change. A rise of $0.9^{\circ} \mathrm{C}$ in rectal temperature and a weight loss of $550 \mathrm{~g}$ was recorded during one hour of exercise. The metabolic energy production increased from the pre-test level of $51 \mathrm{~W} / \mathrm{m}^{2}$ to $244 \mathrm{~W} / \mathrm{m}^{2}$ in the first $5 \mathrm{~min}$ and reached $315 \mathrm{~W} / \mathrm{m}^{2}$ in the last $5 \mathrm{~min}$ of the test. The total energy output during exercise was $289 \mathrm{~W} / \mathrm{m}^{2}$. The heat balance in Fig. 8 was as follows: During exercise; metabolism- $535 \mathrm{~W}$, evaporative heat loss - $370 \mathrm{~W}$, external work-100 W, and rate of body heat storage-30 W when calculated by the equation Mean body temperature $=0.65 \times$ Rectal temperature $+0.35 \times$ Mean skin temperature. The dry heat loss due to conduction, convection and radiation was $35 \mathrm{~W}$. At rest; metabolism-95 W, evaporative heat loss $-47 \mathrm{~W}$, and dry heat loss $-48 \mathrm{~W}$. Some of these data are used in the DISCUSSION. 


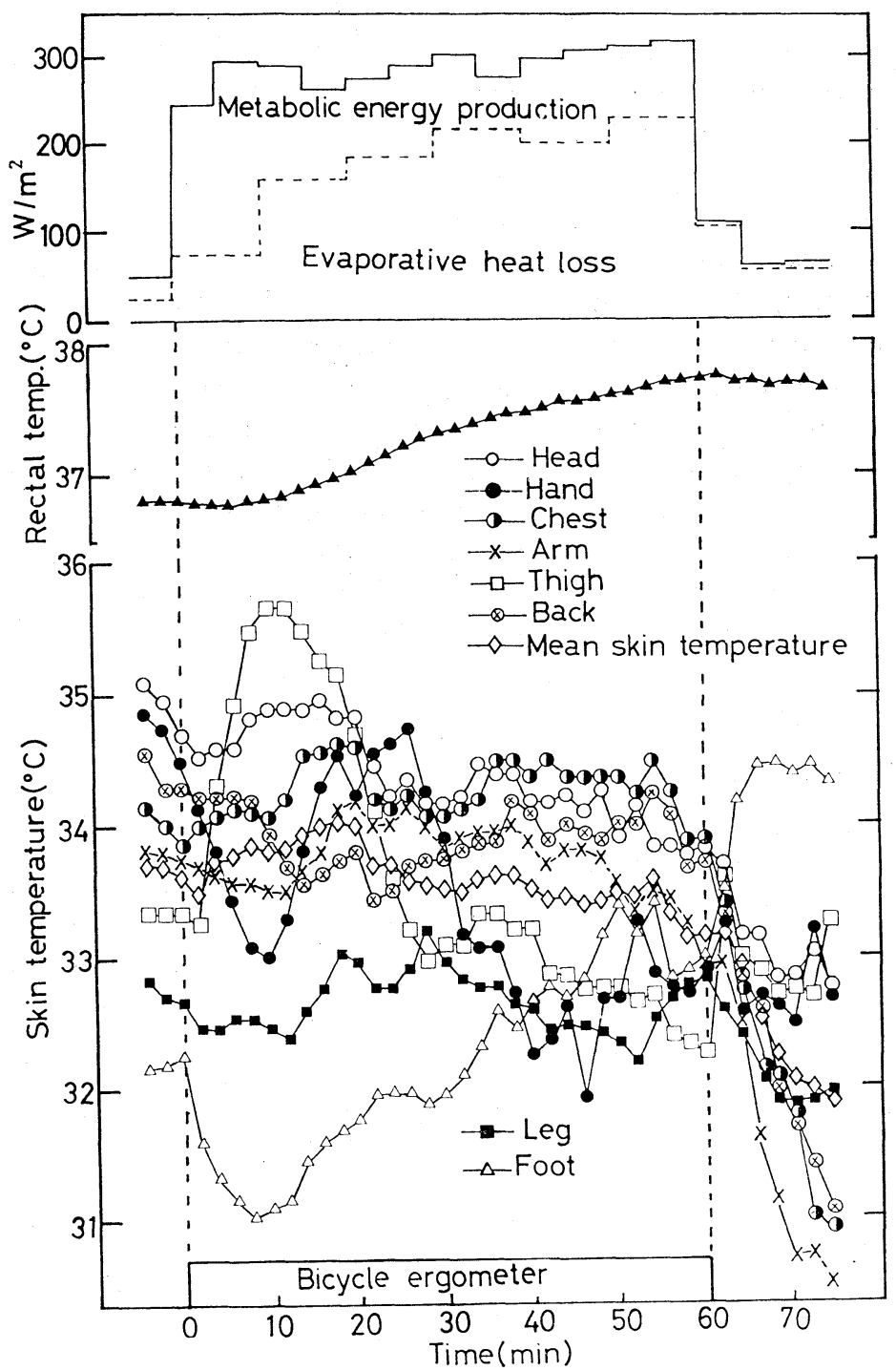

Fig. 8. Metabolism, evaporative heat loss and body temperature during leg pedalling at $100 \mathrm{~W}$ rate. Subj. K.F., $T_{\mathrm{a}} 26^{\circ} \mathrm{C}$, r.h. $60 \%$.

\section{DISCUSSION}

A transitory reduction in skin blood flow at the beginning of work was first mentioned by CHRISTENSEN and NIELSEN (1942a). During the heaviest work, close to the subject's work capacity, they observed the largest and most prolonged reduction in blood flow using a finger plethysmograph. In accordance with the decreased blood flow, a more gradual fall in skin temperature was registered 
simultaneously at the beginning of work. Because of the instantaneous reduction in blood flow, the cause of vasoconstriction was attributed to purely nervous origin. The expectation of work, however, plays no part in evoking vasoconstriction. When finger blood flow was low in a cool environment, there was no decrease in blood flow with the onset of exercise, but there was an increase in the later part of exercise as in a warm environment (CHRISTENSEN and NIELSEN, 1942b). This is consistent with the results shown in Fig. 2, that the drop in skin temperature at the beginning of exercise is not observed in a cool environment.

During the first few minutes of leg exercise, the skin blood flow fell and then gradually increased to above resting levels in the hand (BISHOP et al., 1957; ZELIS et al., 1969; BEVEGÅRD and SHEPHERD, 1966; KAMON and BELDING, 1969). JoHNsON et al. (1974) measured forearm skin blood flow during exercise and suggested that the increase is a net result of competition between vasoconstriction due to exercise and vasodilation due to increasing body temperature. They also mentioned that, 'increased vasoconstrictor outflow to skin reduced its response to thermoregulatory stimuli. This alone would contribute in a major fashion to elevated body temperature in exercise.' The results obtained in this study clearly indicate that work causes a fall in skin temperature over the exercising muscles when the skin is well vasodilated, but produces a rise only when the skin is strongly vasoconstricted. In other words, skin temperature during exercise is dependent on two competitive factors, one is a vasoconstrictor response, which lasts as long as the work is continued, and the other is a vasodilator response as well as increased conductive heat flow from the underlying muscles. The magnitude of these two responses seems to be constant at the same work intensity, but the net responses are apparently modified by the pre-exercise state of cutaneous vasomotor tone. Thus, at higher skin temperature, the constriction effect overwhelmed the dilation effect, while the opposite occurred at lower temperature.

As soon as the subject started to work, the skin temperature began to fall before the onset of sweat secretion and the end of work was followed by a quick rise. Fall in skin temperature is particularly significant in the hand and foot, and the skin area of the exercising muscles. Skin temperature of the right forearm fell in response to left arm exercise. All of these facts indicate that the fall in skin temperature is of nervous origin.

Considering static and dynamic work and the fact that they cause the same rate of heat production, NIELSEN, B. (1975) found that increased sympathetic and adrenal activity were observed during static work, but elevation in core temperature and increase in sweating were the same in both types of work. Her results did not support the hypothesis that a high sympathetic tone should force the core temperature upwards. Light exercise with the arm caused a fall in skin temperature in the arm and chest only, but not in the lower half of the body. These localized responses suggest that reflex vasoconstriction takes place at the level of the spinal cord. With increased intensity of work, more spinal segments 
must be included, causing vasoconstriction in corresponding skin areas.

The possibility that peripheral non-thermal input influences thermoregulatory responses is not improbable. When lying on one side of the body in a hot environment, sweating is inhibited and facilitated on the lowermost and uppermost half of the body, respectively (KunO, 1934). This phenomenon, often called hemihidrosis, is caused by the mechanical pressure exerted by the subject's own body weight on the lateral side of his body surface (TAKAGI and SAKURAI, 1950). Increased respiration during exercise has often been attributed to peripheral afferents from muscles, joint capsules or deep cutaneous sensors. It is not yet known if the same receptors participate in producing increased respiration and lowered skin temperature during exercise. Whatever they are, the fall in skin temperature under discussion must be brought about by augmented vasoconstrictor tone. In a warm environment, sweating is augmented within $2 \mathrm{sec}$ after the beginning of heavy work. The immediate response was observed only when sweating was already present (BEAumont and Bullard, 1963). This result has been interpreted to mean that the response is not due to stimulation of either skin or core thermoreceptors, but rather to some non-thermal stimuli. We speculate that both cutaneous vessels and sweat glands are influenced by increased sympathetic activity, most likely caused by afferents originating in receptors located in exercising or moving tissues, such as joint capsules, or subcutaneous structures. The same neural reflex might modify efferent outflow from the hypothalamus to thermoregulatory effectors within the spinal cord, resulting in facilitation of sweating on the one hand and reduction of vasodilator response on the other hand.

As was discussed, the skin temperature during exercise is the result of competition between the thermoregulatory vasodilation and reflex induced vasoconstriction. The fact that the mean skin temperature does not change during exercise indicates the persistence of increased vasoconstrictor tone. Otherwise, the mean skin temperature would rise, at least in a cool environment where no sweating is expected to occur. On the contrary, even light exercise caused a $3^{\circ} \mathrm{C}$ drop in skin temperature of the epigastrium. Thus, a fall of mean skin temperature of $1^{\circ} \mathrm{C}$, though countered and hidden by regulatory vasodilation, is surely occurring during ordinary exercise. A man at rest for thermal comfort would dissipate heat at the rate of $13.98 \mathrm{kcal} / \mathrm{m}^{2} \cdot \mathrm{hr} \cdot{ }^{\circ} \mathrm{C}$ (CARLSON and HSIEH, 1970). If we use this value and assume that all other thermal variables remain unchanged, the subject in Fig. 8 would dissipate additional heat of $30 \mathrm{~W}$, were his mean skin temperature higher by $1^{\circ} \mathrm{C}$. This amount of heat is equal to the rate of body heat storage in Fig. 8. Virtually, even a small fall in mean skin temperature of less than $1^{\circ} \mathrm{C}$ is expected to cause an upward shift of core temperature to a certain extent because the peripheral tissue conductance would be much higher during exercise than at rest. Thermoregulatory heat loss response during exercise keeps balance with heat production, but the heat loss is reduced by lowered skin temperature brought about by reflex vasoconstriction which is proportional to rate 
of work. The heat dissipated, therefore, is not enough to counter-balance the heat production, thus resulting in an increase in body heat storage.

The rise in internal temperature during work has been discussed with regard to whether the set-point is elevated, lowered or unchanged (SNELLEN, 1972; BLIGH, 1973). The present study supports the view that the set-point is unchanged during work in so far as shift of set-point means some change occurring in the thermoregulatory center such as might be the case during a fever. During work, efferent activities from the heat loss center must be operating in full response to the heat load as they do in the case of heat exposure. But before reaching effector organs, they are interrupted at the spinal level by non-thermal neural activity. Teleologically, the rise in core temperature might be useful in the performance of physical work. The question, however, remains to be solved as to how the elevated core temperature, even though it is caused by non-thermal reflex, can not be balanced out by an increased heat loss response. Although the effect of thermoregulatory heat losis response is partially reduced by reflex vasoconstriction, the magnitude of the priraary response should be equal to that of the total heat production. What is probably regulated within the body is not the body temperature, but the heat balance.

This work was supported in part by grants from the Ministry of Education of Japan.

\section{REFERENCES}

Beaumont, W. Von and Bullard, R. W. (1963) Sweating: Its rapid response to muscular work. Science, 141: 643-646.

Berggren, G. and Christensin, E. H. (1950) Heart rate and body temperature as indices of metabolic rate during work. Arbeitsphysiologie, 14: 255-260.

BEVEGÅRD, B. S. and SHEPHERI, J. T. (1966) Reaction in man of resistance and capacity vessels in forearm and hand to leg exercise. J. Appl. Physiol., 21: 123-132.

Bishop, J. M., Donald, K. W., TAYloR, S. H., and Wormald, P. N. (1957) The blood flow in the human arm during supine leg exercise. J. Physiol. (London), 137: 294-308.

BLIGH, J. (1973) Temperature regulation in mammals and other vertebrates. North-Holland Publ. Co., Amsterdam, pp. 214-227.

Carison, L. D. and HsieH, A. C. L. (1970) Control of energy exchange. Macmillan, New York, p. 56.

Christensen, E. H. and Nielsen, M. (1942a) Investigations of the circulation in the skin at the beginning of muscular work. Acta Physiol. Scand., 4: 162-170.

Christensen, E. H. and Nielsin, M. (1942b) Measurements of blood flow in the skin at rest and during work at varied external temperature. Acta Physiol. Scand., 4: 171-174.

Eichna, L. W., Park, C. R., Nelson, N., Horvath, S. M., and Palmes, E. D. (1950) Thermal regulation during acclimatization in a hot (desert type) environment. Am. J. Physiol., 163: 585-597.

HARDY, J. D. and Dubois, E. F. (1938) The technic of measuring radiation and convection. $J$. Nutr., 15: 461-475.

Johnson, J. M., Rowell, L. B., and Brengelmann, G. L. (1974) Modification of the skin blood flow-body temperature relationship by upright exercise. J. Appl. Physiol., 37: 880886. 
Kamon, E. and Belding, H. (1969) Dermal blood flow in the resting arm during prolonged leg exercise. J. Appl. Physiol., 26: 317-320.

Kuno, Y. (1934) The Physiology of Human Perspiration. Churchill, London, pp. 120-123.

LIND, A. R. (1963) A physiological criterion for setting thermal environmental limits for everyday work. J. Appl. Physiol., 18: 51-56.

NieLSEN, M. (1938) Die Regulation der Körpertemperatur bei Muskelarbeit. Skand. Arch. Physiol., 79: 193-230.

Nielsen, B. and Nielsen, M. (1965) On the regulation of sweat secretion in exercise. Acta Physiol. Scand., 64: 314-322.

NIELSEN, B. (1966) Regulation of body temperature and heat dissipation at different levels of energy- and heat production in man. Acta Physiol. Scand., 68: 215-227.

NiELSEN, B. (1968) Thermoregulatory responses to arm work, leg work and intermittent leg work. Acta Physiol. Scand., 72: 25-32.

Nielsen, B. (1969) Thermoregulation in rest and exercise. Acta Physiol. Scand., Suppl. 323.

Nielsen, B. (1975) Thermoregulation during static work with the legs. Acta Physiol. Scand., 95: $457-462$.

Robinson, S. (1949) Physiological adjustments to heat. In: Physiology of Heat Regulation and the Science of Clothing, ed. by Newburgh, L. H. Saunders, Philadelphia, pp. 193-231.

Saltin, B., Gagge, A. P., and StolwiJk, J. A. J. (1968) Muscle temperature during submaximal exercise in man. J. Appl. Physiol., 25: 679-688.

SNellen, J. W. (1966) Mean body temperature and the control of thermal sweating. Acta Physiol. Pharmacol. Néel., 14: 99-174.

SNellen, J. W. (1972) Set point and exercise. In: Essays on Temperature Regulation, ed. by Bligh, J. and Moore, R. E. North-Holland Publ. Co., Amsterdam, pp. 139-148.

TAKagi, K. and Sakurai, T. (1950) A sweat reflex due to pressure on the body surface. Jap. J. Physiol., 1: 22-28.

WinsLow, C.-E. A. and GAGGe, A. P. (1941) Influence of physical work on physiological reactions to the thermal environment. Am. J. Physiol., 134: 664-681.

Wyndham, C. H., Bouwer, W. V. D. M., Devine, M. G., and Paterson, H. W. (1952-3) Physiological responses of African laborers at various saturated air temperature, wind velocities and rates of energy expenditure. J. Appl. Physiol., 5: 290-298.

Zelis, R., Mason, D.T., and Braunwald, E. (1969) Partition of blood flow to the cutaneous and muscular beds of the forearm at rest and during leg exercise in normal subjects and in patients with heart failure. Circ. Res., 24: 799-806. 